\title{
VÍDEOS CURTOS ANIMADOS: ASPECTOS A SEREM CONSIDERADOS NO ENSINO DE BIOLOGIA
}

\author{
ANIMATED SHORT VIDEOS: ASPECTS TO BE CONSIDERED \\ IN THE TEACHING OF BIOLOGY
}

VÍDEOS CORTOS ANIMADOS: ASPECTOS A SER
CONSIDERADOS EN LA ENSEÑANZA DE BIOLOGÍA

\author{
TALitha TiYomi Lima ${ }^{1}$ \\ Martha Cristina Motta Godinho Netto 2 \\ ${ }^{1}$ Instituto Federal de Educação, Ciência e Tecnologia \\ de São Paulo (IFS). São Paulo/SP - Brasil \\ ${ }^{2}$ Instituto Federal de Educação, Ciência e Tecnologia \\ de São Paulo (IFS). São Paulo/SP - Brasil
}

Resumo A importância do uso de vídeos na educação pode ser indiretamente percebida pela ampliação das plataformas de compartilhamento nos últimos anos. Observa-se o aumento na disponibilização de vídeos curtos animados que poderiam ser usados como recurso didático em diferentes momentos de ensino. Entretanto, a possibilidade de utilização desses vídeos pelos professores pressuporia um entendimento das suas potencialidades pedagógicas. Este trabalho se caracteriza por ser uma pesquisa descritiva e exaustiva que apresenta as características técnicas e estéticas, categorias temáticas e aplicabilidade pedagógica de vídeos curtos de animação sobre temas biológicos nas plataformas internacionais $T e d-E d$ : Lessons Worth Sharing e Kurzgesagt - In a Nutshell.

Palavras-chave: TIC's; Animação; Recursos Didáticos.

Abstract The importance of using videos in education may be indirectly perceived by the expansion of sharing platforms in recent years. It is observed an availability increase of short animated videos that could be used as didactic resource in different teaching moments. However, the possibility of using these videos by teachers would presuppose an understanding of their pedagogical potentialities. This work is characterized by a descriptive and exhaustive research that presents technical and aesthetic characteristics, thematic 
categories and pedagogical applicability of short animation videos on biological subjects in the international platforms Ted-Ed: Lessons Worth Sharing and Kurzgesagt - In a Nutshell. Keywords: TIC's; Animation; Didactic Resources.

Resumen La importancia del uso de vídeos en educación se percebe indirectamente por la recién expansión de plataformas de intercambio. Se aumentó la disponibilidad de videos animados cortos que podrían ser utilizados como recurso didáctico en diferentes momentos de la enseñanza. Pero la posibilidad de utilizar estos vídeos por los docentes implicaría una comprensión de su potencial pedagógico. Este trabajo se caracteriza por una investigación descriptiva y exhaustiva que presenta las características técnicas y estéticas, las categorías temáticas y la aplicabilidad pedagógica de videos animados cortos sobre temas biológicos en las plataformas Ted-Ed Lessons Worth Sharing e Kurzgesagt - In a Nutshell.

Palabras claves: TiC's; Animación; Recursos Didácticos.

\section{INTRODUÇÃo}

A popularização do uso de vídeos no ensino de Ciências e Biologia aconteceu, segundo Moran (1995), em meados da década de 1990, quando foi possível integrar o uso de televisão e aparelhos de videocassete nas salas de aula. Entretanto, já naquela época o autor ressaltava que era preciso atentar para o uso consciente do recurso visando impedir a sua aplicação equivocada no ambiente escolar.

De fato, no ensino de Ciências e Biologia, os vídeos são normalmente utilizados, entre outras situações, para importantes fins pedagógicos pois costumam ser apresentados para sensibilização (despertar do interesse ou motivar os alunos para a aprendizagem ); para ilustração (mostrar fatos, situações, detalhes sobre os seres vivos, equipamentos); para videoaulas simuladas (simular experimentos ou processos complexos e também para mostrar ou fixar conteúdos) (MORAN; MASSETO; BEHRENS, 2000).

Quando, nos dias atuais, se considera o uso de vídeos em sala de aula, se percebe a existência de um possível conflito entre o modelo tradicional do seu uso pedagógico (geralmente, associado ao uso do computador e/ou projetor) e a forma como as crianças e jovens "nativos digitais" utilizam as mídias, compartilham arquivos, usam telefonia móvel e trocam opiniões em redes sociais (com frequência, mensagens e vídeos curtos com muitas informações, música e sequência rápida de imagens) (TULGAN, 2013). Entretanto, segundo Sousa; Moita e Carvalho (2011), é relativamente comum o uso didático de vídeos obtidos em sítios da internet (gravados ou on-line) ou mesmo criados pelos próprios professores e alunos. Essa prática, de certa forma, reflete as tendências de mudanças nas formas de comunicação e interação em redes sociais da sociedade moderna (SOUZA, 2014).

Nesse contexto, sítios de compartilhamento de vídeos, por exemplo, o YouTube, ampliaram as possibilidades de divulgação e popularização de vídeos amadores, acadêmicos e profissionais (SCHNEIDER; CAETANO; RIBEIRO, 2012). Por sua vez, muitos recursos didáticos (inclusive vídeos) também passaram a ser organizados em bancos de dados 
institucionais, nacionais e internacionais, visando a geração de repositórios de recursos didáticos para uso público (BINOTTO; BASSO, 2012).

A medida da importância do uso desses recursos na educação pode ser indiretamente percebida pela constatação da existência de várias plataformas de compartilhamento de objetos educacionais digitais (JUNIOR; BARROS, 2005). No Brasil, o Portal do Professor (http://portaldoprofessor.mec.gov.br/index.html), mantido pelo Ministério da Educação, e o Banco Internacional de Objetos Educacionais (http://objetoseducacionais2.mec.gov.br/), surgiram como uma tentativa de gerar ambiente para a troca de experiências e material didático entre professores do ensino básico (JUNIOR; BARROS, 2005 e BIELSCHOWSKY; PRATA, 2010).

Em uma busca rápida nas duas plataformas, realizada pelo nosso grupo no início de 2018, foram encontrados, em média, 250 vídeos disponíveis, o que indica uma boa oferta numérica de opções. Porém, as plataformas forçam o professor a fazer download dos vídeos antes mesmo de poder assistí-los e selecioná-los para fins didáticos. Além disso, ressalta-se que os vídeos mais recentes disponíveis em ambas as plataformas foram publicados em 2013, o que indica uma dificuldade de atualização de conteúdo.

Contudo, quando se busca por vídeos para possíveis fins didáticos, as plataformas supracitadas não são as únicas disponíveis na internet. Plataformas internacionais educacionais de acesso livre, como o YouTube Edu (plataforma que surgiu da parceria entre a Fundação Lemann e o Google, em 2013, que reúne diversos vídeos educativos e videoaulas, mas poucas animações, https://goo.gl/hSpLJH), TED-Ed: Lessons Worth of Sharing (plataforma gratuita internacional de compartilhamento de vídeos e criação de aulas interativas, lançada em 2012, https://ed.ted.com/) e Kurzgesagt - In a Nutshell (canal do YouTube e estúdio de design alemão, lançado em 2013, https://goo.gl/ixgePz) estão se tornando cada vez mais presentes dentro das salas de aula, com suas animações e videoaulas. Uma das características marcantes dessas plataformas é o acesso on-line sem a necessidade de realização de download ou cadastro. Além disso, a geração de novos recursos mostra-se mais atualizada quando comparada com as plataformas brasileiras.

Entre os vários formatos de vídeo disponíveis nesses sítios destacam-se, pela quantidade, aqueles com duração menor que dez minutos e estética (design) que se assemelha aos desenhos animados. A suposta predileção das plataformas em utilizar esse tipo de vídeo (curto animado) poderia estar vinculada à necessidade de atualização dos formatos de vídeos tradicionais às formas de comunicação e interação do público jovem de hoje. Mas, antes de se usar esses vídeos nas escolas, seria preciso compreender em quais aspectos eles poderiam contribuir para o processo de ensino e aprendizagem. $\mathrm{O}$ entendimento das características dos vídeos curtos de animação disponíveis nas referidas plataformas seria, então, pré-requisito obrigatório para a escolha pedagógica mais assertiva e o uso dos mesmos como recursos didáticos.

Foi partindo desse contexto que o presente trabalho objetivou avaliar os vídeos curtos animados sobre temas biológicos disponíveis no TED-Ed: Lessons Worth Sharing e no Kurzgesagt - In a Nutshel, pretendendo: (a) categorizar os vídeos curtos animados pelos tipos 
e temas biológicos; (b) identificar as características técnicas e estéticas presentes nos vídeos curtos animados acerca de temas biológicos; (c) categorizar os vídeos curtos animados pelos conteúdos pedagógicos relacionados aos temas biológicos e; (d) categorizar os vídeos curtos animados considerando as possibilidades de formas de uso do recurso didático.

\section{Metodologia}

Este trabalho se caracteriza por ser uma pesquisa descritiva (ROSA, 2013) e utilizará os dados obtidos por busca exaustiva de vídeos curtos de animação sobre temas biológicos nas plataformas internacionais. Na Figura 1, encontra-se resumido o processo de seleção e categorização dos vídeos, que será explicado com mais detalhes a seguir.

A escolha das plataformas foi realizada a partir da leitura "flutuante" (ROSA, 2013), que permitiu estabelecer o entendimento da natureza dos ambientes virtuais, seu funcionamento e lógica de acesso. A seleção foi feita garantindo-se a exaustividade, a representatividade, a homogeneidade e a escolha dos objetos de pertinência para o estudo (BARDIN, 2016, p. 125). Aplicou-se, para isso, os seguintes critérios de inclusão: (1) existência de vídeos curtos de animação publicados nos últimos cinco (5) anos (correspondendo ao período de 2012 a 2017); (2) não obrigatoriedade de cadastro prévio do usuário; (3) disponibilização dos vídeos para visualização on-line e/ou por meio de download e (4) disponibilidade de incorporação automática de legendas.

Dessa forma, foram selecionadas as plataformas: YouTube Edu, Kurzgesagt - In a Nutshell e TED-Ed: Lessons Worth of Sharing. Porém, apenas as plataformas TED-Ed: Lessons Worth of Sharing e o Kurzgesagt - In a Nutshell apresentaram uma quantidade mínima de vídeos curtos animados e foram mantidas na pesquisa. Já a plataforma YouTube Edu foi excluída do trabalho por conter maior quantidade de videoaulas ou vídeos não animados.

A seleção inicial dos vídeos das plataformas utilizou critérios de inclusão específicos de forma combinada, a saber: (1) presença de vídeos contendo exclusivamente desenhos animados; (2) vídeos publicados até dezembro de 2017 e; (3) vídeos com tempo máximo de duração de sete minutos. Os dados obtidos foram compilados em diversas tabelas em planilha Excel. Os 327 vídeos selecionados nessa primeira etapa foram empregados nas etapas subsequentes.

A separação dos vídeos, de acordo com as áreas subáreas e subcategorias de subáreas do conhecimento, foi feita levando-se em consideração o documento oficial do Conselho Nacional de Desenvolvimento Científico e Tecnológico (CNPq), agência do Ministério da Ciência, Tecnologia, Inovações e Comunicações (MCTIC) (CNPQ, 2005). Essa categorização foi realizada a partir da análise das imagens e conteúdo de cada vídeo para a identificação da área predominante. Os vídeos que não possuíam uma área predominante foram categorizados em uma classe não existente nos documentos do $\mathrm{CNPq}$, e criada especialmente para a ocasião, denominada "Integrado" (que agrupou todos os vídeos que mostravam um equilíbrio de conteúdos de duas ou mais subáreas da Biologia). As subcategorizações seguiram procedimento semelhante. 
Figura 1 - Fluxograma resumo do processo de seleção e categorização dos vídeos curtos animados adaptado da metodologia de busca exaustiva segundo Rosa, 2013.

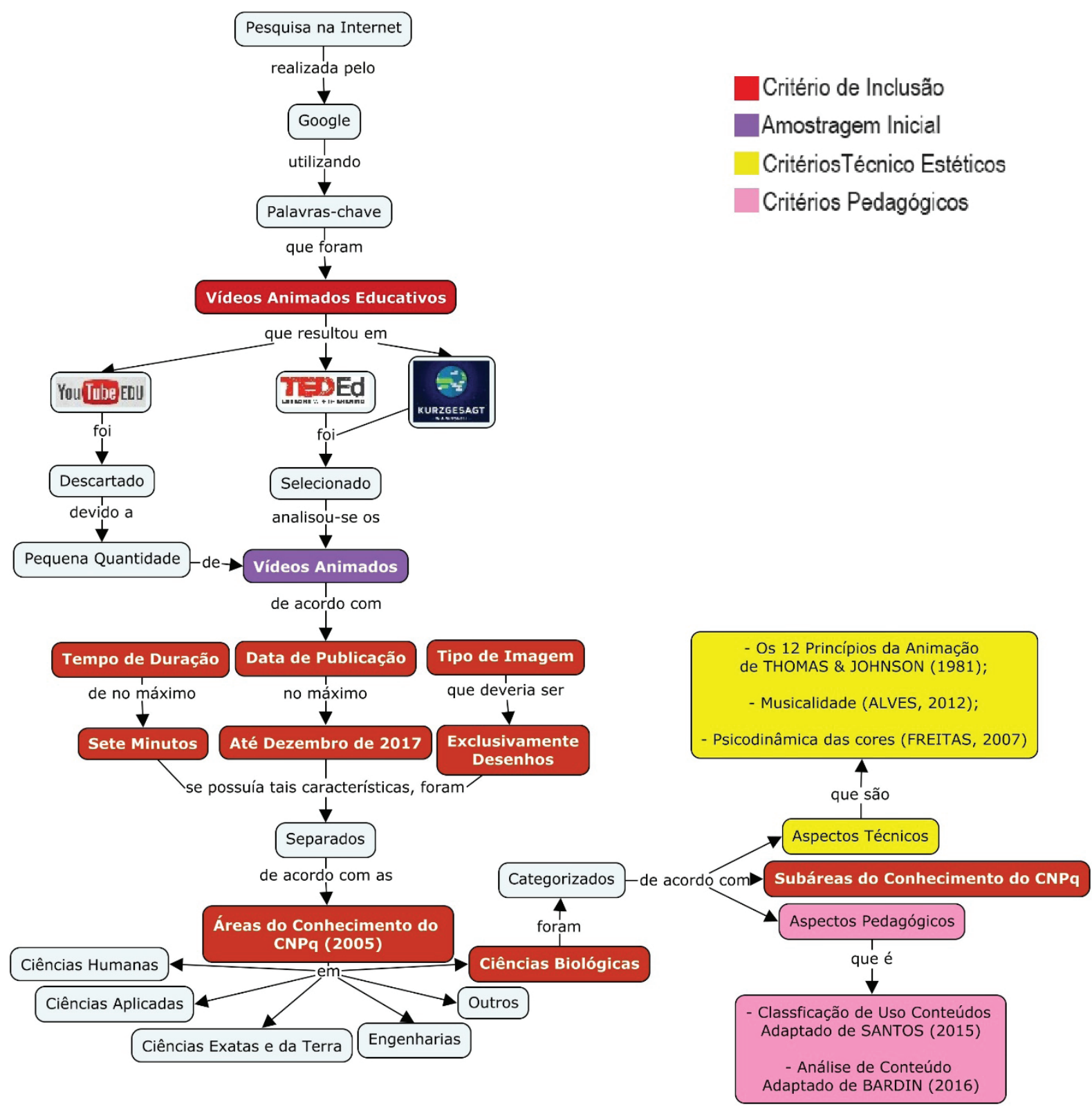

Fonte: As autoras. 
Os vídeos curtos de animação também foram analisados segundo seus aspectos técnicos e estéticos definidos nos "12 Princípios da Animação", de Thomas \& Johnson (1981), que são:

1. Comprimir e Esticar: Objetos no mundo real têm certa flexibilidade e esse princípio prevê que essa naturalidade de mudança na forma dos objetos, devido à sua flexibilidade, seja mantida na animação. Objetos orgânicos, por exemplo, apresentam um nível maior de flexibilidade em sua forma do que objetos não orgânicos.

2. Antecipação: Toda ação é precedida por uma "antecipação", que é um movimento que precede uma ação principal, por exemplo: para pular, primeiramente é preciso dobrar os joelhos, essa ação de dobrar os joelhos é a "Antecipação".

3. Encenação: É o princípio que prevê que as cenas das animações devem ser claras, sem "ruídos", ou seja, uma animação precisa ser pensada para harmonizar todos os elementos existentes nela, de maneira que informação alguma se perca durante o processo de reprodução.

4. Animação Direta/Pose-to-pose: Princípio que define o tipo de animação que pode ser empregado. Ou seja, consiste na movimentação de um objeto feita por um computador, de maneira que os movimentos intermediários entre a posição final e a inicial sejam simulados. Já o princípio pose-to-pose é um tipo de animação em que cada movimento do objeto é desenhado quadro a quadro.

5. Continuidade: Princípio que define a importância da continuidade da movimentação de elementos secundários após a parada da ação principal, para dar fluidez, coerência e naturalidade à cena. Por exemplo, ao chover os personagens se molham, empregando esse princípio, na cena seguinte, quando o personagem se abriga, gotas d'água devem continuar escorrendo e pingando do personagem.

6. Aceleração: No mundo real, todo objeto em movimento sofre uma aceleração e desaceleração gradativa.

7. Movimento em arco: Tudo à nossa volta se movimenta por meio de movimentos circulares. Esse princípio prega que, para ser mais suave e natural, é preciso que cada movimemento ocorra em arcos.

8. Ação Secundária: Princípio que prevê que todo movimento principal resulta em outros secundários, por exemplo, o movimento de caminhar ocasiona secundariamente um balançar dos cabelos do personagem.

9. Temporização: Basicamente é o "ritmo", ou seja, o tempo que uma ação demora para ser executada, levando em consideração princípios básicos da física, para que este tenha coerência, ou incoerência se for proposital.

10. Exagero: Consiste na distorção de objetos, ou de ações, que estão fora do escopo natural das coisas no mundo real. Geralmente, pode causar estranheza e chamar mais atenção para aquele elemento que está sendo exagerado. Também pode ser utilizado para dar ênfase a emoções de personagens.

11. Desenho Volumétrico: É a ilusão de volume que a animação pode trazer. São ilusões óticas causadas por desenhos na maioria em perspectiva ou sombreadamente e que dão a impressão de uma animação tridimensional. 
12. Apelo: É considerado o princípio que dá vida à animação, aquilo que traz pregnância, que mantém o observador interessado no vídeo. Podem ser empregadas diversas manobras para se alcançar esse princípio, desde ilustrações diferentes, cores, sons, a animações bem feitas.

Além dos "12 Princípios da Animação", os vídeos foram analisados segundo a psicodinâmica das cores (FREITAS, 2007), que trata da influência das cores no psicológico de adultos e jovens. De acordo com o referencial escolhido, as cores consideradas mais "vibrantes" e "fortes" seriam aquelas que chamariam, inconscientemente, mais a atenção das crianças.

Outro aspecto técnico-estético analisado foi a trilha sonora que, segundo ALVES (2012), deveria:

Despertar no espectador um "ponto de escuta" é também aumentar a complexidade de seu "ponto de vista", uma vez que a capacidade sensorial de cada ser é que molda sua cultura auditiva e provém das experiências particulares acumuladas (ALVES, 2012).

Ou seja, a trilha sonora deveria estimular outros sentidos, além do visual, em uma produção multimídia e pode aguçar a percepção do espectador em torno do assunto que está sendo tratado naquela produção, o que beneficia como um todo a atenção ao vídeo.

Finalmente, para analisar as possibilidades de formas de uso pedagógico dos vídeos, foram aplicados parâmetros de classificação taxônomica de vídeos de Santos (2015), que consistem em classificar os vídeos em relação aos aspectos pedagógicos de conteúdo em "Vídeos para Introduzir e Apresentar" (quando exibe definições) "Vídeos de Aplicação" (quando mostra problematização de conteúdos e/ou métodos), "Vídeos de Fixação ou Reforço" (quando apresenta exercícios e/ou retoma constantemente definições).

Um segundo nível de análise envolveu o aprofundamento dos significados dos conteúdos e foi feito utilizando-se os princípios para análise de conteúdo adaptados a partir daqueles determinados por Bardin (2016). O referencial metodológico original determina o estabelecimento de três grandes eixos base para analisar conteúdos, que foram: o Conceito Inicial, o Conceito Intermediário e o Conceito Final, definidos a partir do estabelecimento de palavras-chave encontradas ao longo dos textos das transcrições das narrações dos vídeos. A repetição dessas palavras determinou o seu nível de importância, e, portanto, se é um conceito inicial, intermediário ou final.

A partir dessa definição foram feitas adaptações na metodologia, de forma que os conceitos fossem definidos não mais pela repetição de palavras, mas sim pelo seu significado. O Conceito Inicial tornou-se o Tema Eixo, o Conceito Intermediário tornou-se o Contexto e o Conceito final tornou-se o grande grupo que os conceitos intermediários poderiam ser agrupados.

Essa análise envolveu apenas os vídeos da área de conhecimento mais representada (Fisiologia) na plataforma $T E D-E d$. O Conceito Inicial (ou Tema Eixo) dos vídeos, muitas vezes, estava expresso explicitamente no próprio título da animação. O Conceito Inter- 
mediário foi definido pelo contexto em que o conceito inicial era abordado. O Conceito Final foi considerado como sendo aquele no qual os conceitos intermediários poderiam ser agrupados. Os vídeos também foram categorizados, segundo as subáreas e áreas de conhecimento do $\mathrm{CNPq}$ e quanto à abordagem (histórica/científica ou científica).

Todos os vídeos foram assistidos pelas autoras deste trabalho e todos os aspectos técnicos e pedagógicos foram analisados segundo a sua presença ou ausência. Os dados obtidos foram compilados em diversas tabelas em planilha Excel.

\section{RESUltados E DISCUSSÃO}

Os resultados demonstram que, do total de 327 vídeos analisados, a plataforma TED-Ed: Lessons Worth of Sharing produziu e hospedou 257 vídeos, sendo 253 originais (produzidos pela própria plataforma), e quatro selecionados (produzidos por outros). Já a plataforma Kurzgesagt-In a Nutshell produziu e hospedou um total de 70 vídeos originais. Inicialmente, cogitou-se se essa diferença não seria reflexo da diferença no tempo de existência das plataformas. Entretanto, a plataforma $T E D-E d$ foi criada em 2012, apenas um ano antes da plataforma Kurzgesagt, e isso, não necessariamente justificaria a diferença de $73 \%$ no total de publicações no período. Alternativamente, entendeu-se que o maior volume de publicação da plataforma $T E D-E d$ provavelmente estaria relacionado ao fato de ela ter sido intencionalmente criada para auxiliar os professores e estimular a curiosidade dos alunos (TED-ED, 2018), enquanto que a plataforma Kurzgesagt foi criada por um estúdio de design que se propôs a apresentar de forma inovadora projetos próprios que exibem um viés educacional informativo (KURZGESAGT, 2018).

\section{CARACTERIZaÇão dos temas dos vídeos CURTOS ANimados}

Aproximadamente, 225 vídeos da plataforma TED-Ed abordam temas de Ciências Biológicas, correspondendo a $88 \%$ do total, enquanto que na plataforma Kurzgesagt apenas doze (17\% do total) vídeos tratam dessa área do conhecimento. Quando se analisa a frequência de produção de vídeos de Biologia ao longo dos anos, verifica-se que a produção e publicação anual da plataforma $T E D-E d$ não parece ter qualquer tipo de padrão, uma vez que houve um aumento progressivo de produção até 2015 (quando foram publicados o máximo de 53 vídeos no ano), e depois uma queda de produção que permaneceu estabilizada em torno de 40 vídeos nos anos subsequentes. Já a plataforma Kurzgesagt disponibilizou anualmente três vídeos curtos de animação desde o ano de sua criação, totalizando 12 até o ano de 2017 (Figura 2).

Em relação às subáreas do conhecimento, pôde-se notar que nem todas as subáreas das ciências biológicas estão igualmente representadas, sendo que a maior parte dos vídeos disponibilizados na plataforma $T E D-E d$ aborda temas de Fisiologia (34\%), seguidos daqueles relativos à Zoologia (18\%), Biologia Geral (10\%), Morfologia (9\%), Genética (6\%), MicroBiologia e Ecologia (5\%), Biofísica (4\%), Bioquímica (3\%), Botânica (2\%) e Farmacobiologia, Imunologia, Parasitologia e Integrado (1\%).

186 Comunicações | Piracicaba | v. 26 | n. 2 | p. 179-195 | maio-ago. 2019 
Na plataforma Kurzgesagt predominam os vídeos de Imunologia, MicroBiologia e Morfologia, que representam 51\% (sendo que cada subárea representa $17 \%$ do total); Biofísica representa 9\%; e Fisiologia, Ecologia, Farmacobiologia e Parasitologia representam $32 \%$ (sendo que cada subárea representa $8 \%$ ) dos vídeos disponíveis.

Figura 2 - Gráfico comparativo da produção anual de vídeos com temas biológicos nas plataformas TED-Ed e Kurzgesagt - In a Nutshell

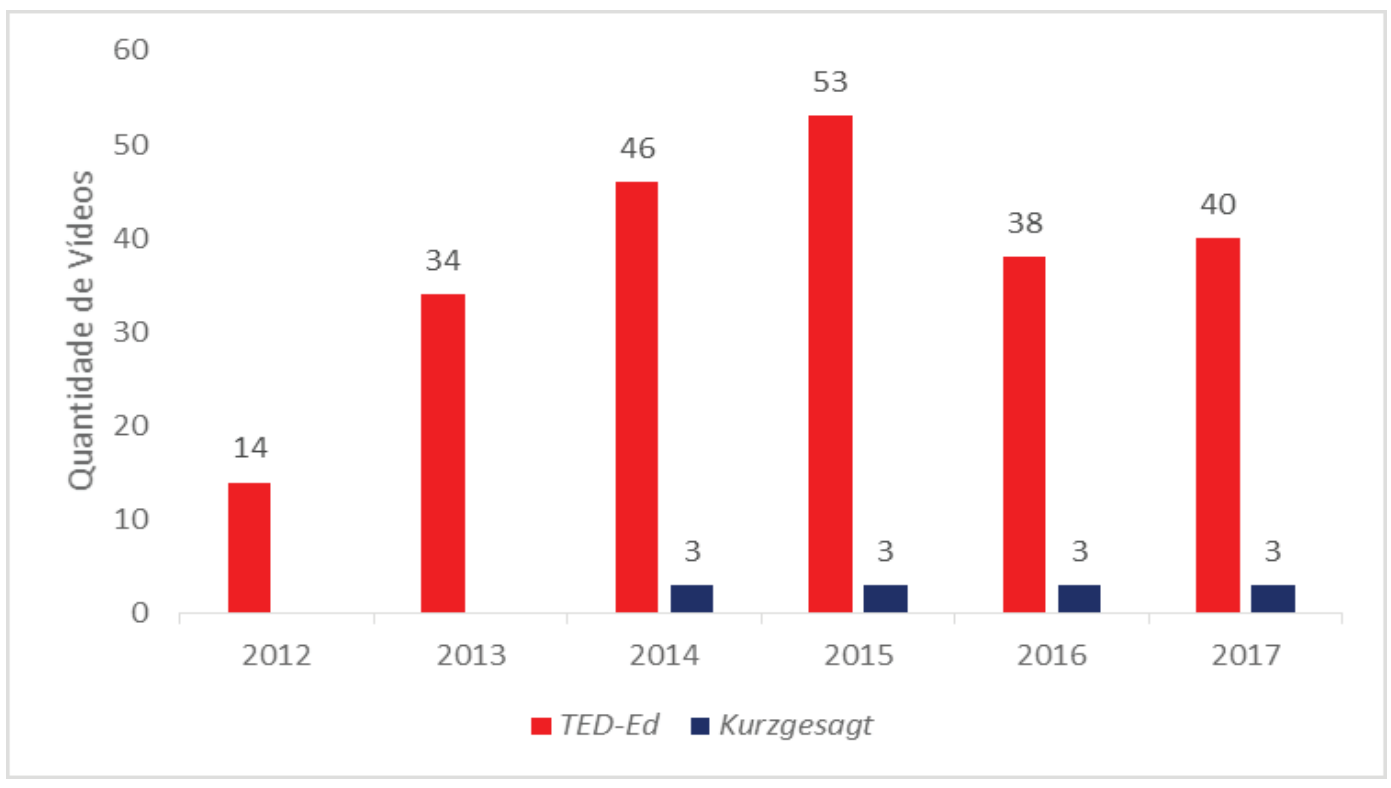

Fonte: As autoras.

\section{IDENTIFICAÇÃO DAS CARACTERÍSTICAS TÉCNICAS E ESTÉTICAS NOS VÍDEOS CUR- TOS ANIMADOS SOBRE TEMAS BIOLÓGICOS}

Os infográficos das Figuras 3 e 4 resumem (em porcentagens) os doze princípios da animação com mais frequência encontrados nos vídeos curtos animados sobre assuntos biológicos da plataforma Kurzgesagt e TED-Ed, respectivamente.

Os resultados indicam que os vídeos animados que tratam de temas biológicos da plataforma Kurzgesagt apresentam oito dos doze princípios da animação, sendo que "antecipação" e "encenação" estão garantidos em todos os vídeos. O princípio de "movimento em arco" está presente em 90,9\% e o de "temporização" e "ação secundária" em 81,6\% dos vídeos. Os demais princípios ("animação direta", "aceleração" e "apelo") estão presentes em $63,4 \%$ dos vídeos animados. A ausência dos princípios "comprimir e esticar", "continuidade", "exagero" e "desenho volumétrico" parece seguir uma escolha de estilo de animação da plataforma Kurzgesagt, uma vez que nenhum vídeo animado dessa plataforma exibe tais princípios. 
Figura 3 - Infográfico dos 12 Princípios da Animação nos Vídeos do Kurzgesagt. (O tamanho da barra corresponde ao percentual de identificação de cada um dos princípios.)

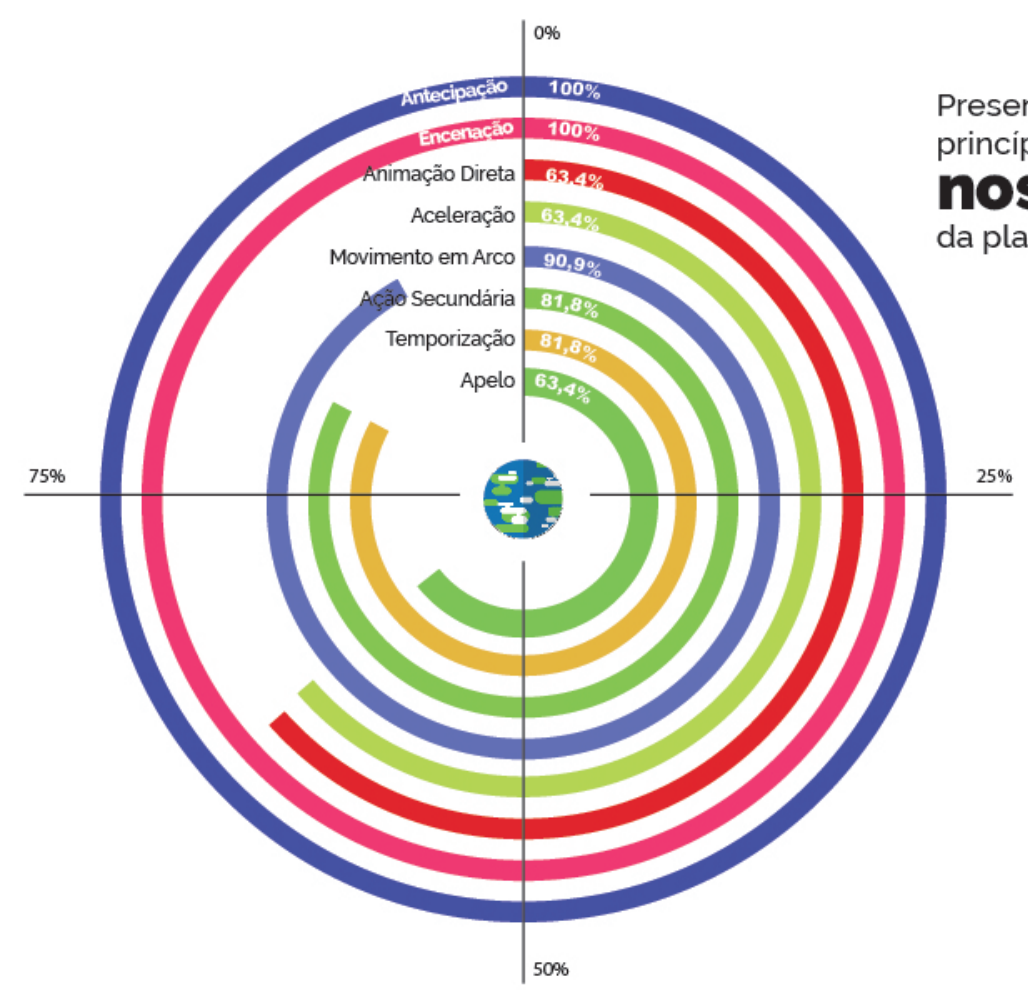

\section{Principios não encontrados:}

- Comprimir e Esticar; - Continuidade;

- Exagero;

- Desenho Volumétrico.

Fonte: Dados das autoras e criação do infográfico por Fabricio Vilela de Oliveira.

Essa escolha pode estar relacionada à intenção dos produtores ao cuidado em evitar ao máximo possíveis erros conceituais, que poderiam ser incorporados às animações por ocasião dos princípios citados. Por exemplo, a ausência do princípio do "exagero" evita que proporções ou ações exageradas sejam passadas no vídeo, evitando gerar ideias equivocadas de dimensões biológicas fora da realidade e movimentos não naturais. Já no caso do princípio "desenho volumétrico", sua ausência poderia estar relacionada ao fato de o vídeo ser um cartoon, um desenho animado, e desenhos animados, na sua maioria, são bidimensionais e não tridimensionais. Essa ausência, entretando, precisa ser considerada pelo professor que venha a usar esses vídeos, uma vez que a incorporação da tridimensionalidade é um aspecto importante em muitos contextos biológicos.

Os princípios "Comprimir e esticar" e "Continuidade", por sua vez, estão mais ligados a aspectos técnicos de custo de produção. Esses princípios são mais complexos e dependem de computadores mais potentes para serem incorporados ou de mão de obra mais especializada para desenhar mais posições de objetos. A ausência desses princípios nos vídeos poderia estar relacionada a uma adequação de infraestrutura e indisponibilidade de pessoal treinado. 
No que se refere às cores e musicalidade, os vídeos curtos animados da plataforma Kurzgesagt caracterizam-se por serem muito coloridos e sonoros. A musicalidade é observada tanto pela existência de música de fundo (trilha sonora) como pela narração que conferem ritmo às animações. As duas características combinadas tendem a ativar dois sentidos de uma vez, a visão e a audição, e isso geralmente aumenta a pregnância da animação.

Dessa forma, considerando-se todos os aspectos técnicos e estéticos identificados, entende-se que os vídeos da plataforma Kurzgesagt poderiam ser interessantes objetos de aprendizagem, pois poderiam aumentar a motivação e a curiosidade dos alunos para os temas de estudo.

Já no caso dos vídeos da plataforma $T E D-E d$, observa-se a presença de todos os 12 princípios de animação quando os 225 vídeos são analisados em conjunto (Figura 4).

Entretanto, nem todos os princípios estão exibidos em todos os vídeos. Há uma maior variação da frequência de identificação dos princípios, como é o caso do princípio da "aceleração", presente em 70,5\% dos vídeos, enquanto que o "exagero" está evidente apenas em $8,8 \%$ dos vídeos, sendo que nenhum princípio está $100 \%$ presente nas produções do $T E D$ $-E d$. A variação de predominância de alguns princípios em detrimento de outros poderia ser atribuída a dois fatores: 1) custo de produção da animação e/ou; 2) preferência dos autores.

Figura 4 - Infográfico dos 12 Princípios da Animação nos Vídeos do TED-Ed. (O tamanho da barra corresponde ao percentual de identificação de cada um dos princípios.)

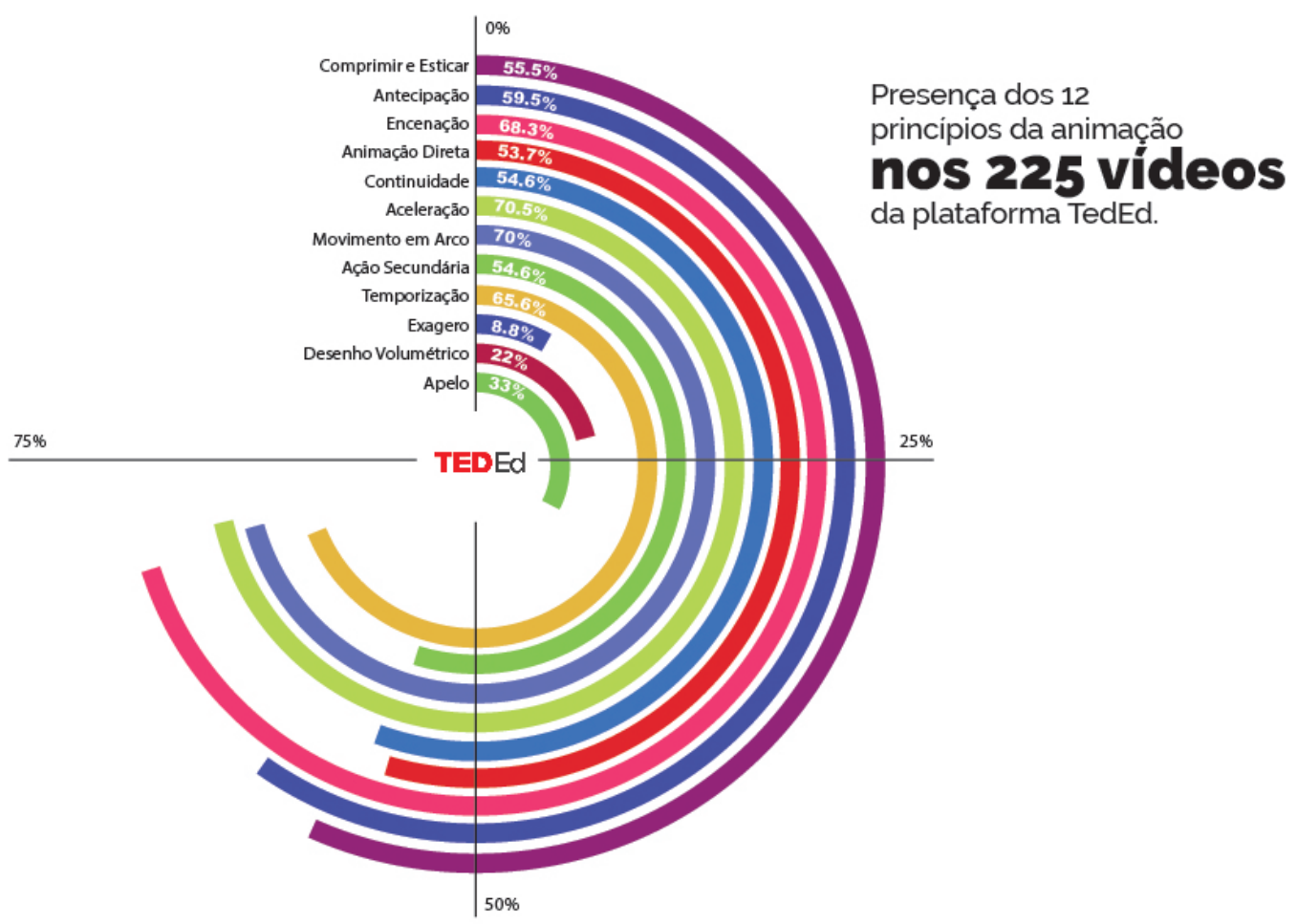

Fonte: Dados das autoras e criação do infográfico por Fabricio Vilela de Oliveira. 
Outro aspecto recorrente nos vídeos animados disponibilizados pelo TED-Ed é a preferência por não trabalhar com trilha sonora vinculada aos vídeos narrados (com a presença apenas de alguns efeitos pontuais de sonoplastia), além de trabalhar com cores mais suaves e tons pastéis, ou até mesmo utilizar cores vibrantes pontuais, em apenas alguns objetos da animação.

Tomadas em conjunto, as escolhas por inclusão de alguns princípios de animação e ausência de sonorização talvez pudessem responder, em parte, pelo alto número de vídeos animados publicados anualmente pelo TED-Ed. Nessas condições, tanto os custos como o tempo de produção poderiam ser reduzidos, mas o princípio "apelo" ficaria comprometido nesse tipo de produção. Dessa forma, seria possível considerar que a pregnância dessas animações junto ao público mais jovem não fosse totalmente satisfatória para a manutenção da atenção dos espectadores. O uso desses vídeos em momentos de ensino precisaria levar em consideração essa situação. Por sua vez, a possibilidade do uso desses vídeos com características técnicas e estéticas potencialmente menos atrativas ao público jovem em situações de ensino poderia ser assegurada, considerando-se outros aspectos, como a roteirização (sequência de apresentação do conteúdo), a abordagem da "história" contada (científica, histórica, econômico-social), a narrativa (científica ou não científica) que poderiam minimizar o nível mais baixo de "apelo".

Cabe ressaltar que nem sempre os vídeos curtos animados precisam, necessariamente, apresentar todos os 12 Princípios da Animação para serem elegíveis. Mas a escolha didática de vídeos curtos animados que considerem os parâmetros técnicos e estéticos pode auxiliar o professor na geração de um momento de ensino que aproxime o público aos objetivos pedagógicos específicos. Por exemplo, vídeos com musicalidade e ritmo acelerado podem ser mais apropriados para chamar a atenção e motivar a aprendizagem de algum assunto. Já vídeos com menos efeitos sonoplásticos e design menos intensos poderiam ser mais apropriados para a fixação de algum tema ou para sensibilização e envolvimento de público com maior dificuldade de interação com mídias digitais

\section{CategorizaÇão dos vídeos Curtos animados Quanto aOS Conteúdos Ped- AGÓGICOS E POSSIBILIDADES DE FORMAS DE USO COMO RECURSO DIDÁTICO}

Os resultados indicam que a maior parte dos vídeos animados de Ciências Biológicas $(67 \%)$ das duas plataformas poderia ser utilizada como recursos didáticos voltados à "Introdução e Apresentação" de temas de aulas pois exibiram um ou mais descritores específicos para essa categoria, a saber: objetivo, revisão, apresentação, conteúdo situado, definição e exemplos. Por sua vez, $32 \%$ dos vídeos animados poderiam ser utilizados para "Aplicação de conteúdo", pois mostraram forte viés para: problemática, representações, regras/métodos (além de apresentação, conteúdo situado e exercícios). Finalmente, apenas $1 \%$ dos vídeos foi reconhecido como d possibilidade de uso para "Fixação", (1\%).

O fato de apenas $1 \%$ dos vídeos serem aplicáveis à "Fixação" demonstra uma tendência das plataformas a privilegiar a produção de animações que tenham uma aplicabili-

190 Comunicações | Piracicaba | v. 26 | n. 2 | p. 179-195 | maio-ago. 2019 
dade pedagógica diferenciada daquela de repetição, que geralmente é muito utilizada em trabalhos de fixação. Animações de "Introdução/Apresentação" e "Aplicação" poderiam ser mais facilmente incorporadas ao planejamento de aulas. pois não estariam atreladas a aspectos exclusivos de memorização definidos para contextos específicos já passados pelo professor previamente.

Ainda buscando verificar as potencialidades de uso dos vídeos no ensino de Biologia, optou-se por analisar seus conteúdos a partir da adaptação dos preceitos definidos por Bardin 2016). O $\boldsymbol{n}$ amostral dessas análises incluiu apenas os 75 vídeos da grande área de Fisiologia, pois foram os com mais frequência publicados na plataforma $T E D-E d$.

A Figura 5 apresenta uma amostra da categorização realizada, na qual cada um dos vídeos foi analisado quanto ao tema-eixo (conceito inicial) que foram agrupados em contextos (conceito intermediário) para posterior novo agrupamento em conceitos finais.

Observando-se os conceitos iniciais, percebe-se a inexistência de temas-eixo repetidos e isso poderia ser interpretado como uma preocupação em se garantir a diversidade de assuntos. Entretanto, quando os conceitos primários são agrupados em conceitos secundários, percebe-se que há alguns contextos predominantes.

A maior parte dos vídeos de fisiologia da plataforma TED-Ed trata dos conceitos iniciais num contexto predominante de "funcionamento" (46\%), "ação" (12\%), "função" (11\%) e "alteração" (11\%). Poucos contextos se voltam para "aplicação" (1\%) ou "relação" (1\%). Esses resultados indicam que, potencialmente, os vídeos do TED-Ed poderiam oportunizar aos alunos um momento de ensino para o entendimento mais dinâmico de eventos complexos da fisiologia que não conseguem ser plenamente compreendidos com figuras sem movimento (nos livros ou slides). Entretanto, se o objetivo do ensino for apresentar aplicações ou relações do conceito inicial, será preciso escolher outra fonte de vídeos, pois a plataforma $T E D-E d$ não disponibiliza grande oferta desse tipo de material.

Outro aspecto que merece destaque se refere à distribuição de vídeos da plataforma $T E D-E d$ em diferentes conceitos finais relacionados à grande área de Fisiologia. Apesar da existência de 21 conceitos finais diferentes, há o predomínio de vídeos sobre fisiologia do sistema nervoso (31\%), seguido da fisiologia do cérebro (18\%) e fisiologia do sistema digestório (11\%) que, em conjunto, correspondem a 60\% dos vídeos sobre fisiologia. Quando se analisam os contextos desses vídeos, percebe-se que a maioria se volta para a apresentação do funcionamento do sistema nervoso, do cérebro ou do sistema digestório.

Ainda, considerando-se os vídeos de fisiologia da plataforma $T E D-E d$, percebe-se que há o predomínio de vídeos animados com abordagem científica $(84 \%)$ e poucos com abordagem histórico/científica (16\%). Esses dados indicam que, independentemente do professor ter a oportunidade de encontrar vídeos científicos adequados, será mais difícil obter animações que incorporem personagens, datas e eventos históricos.

Apesar da dificuldade de se encontrar pesquisas que estabeleçam uma discussão profunda sobre parâmetros a serem utilizados na escolha de vídeos de animação para uso didático na área de Ciências Biológicas (SOUSA et al., 2011), nossos resultados mostram que as animações das plataformas pesquisadas apresentam a possibilidade de serem usadas com 
diferentes objetivos. Ressalta-se a possibilidade de seu uso visando a "Introdução/Apresentação" e "Aplicação" de conhecimentos. Além disso, o fato de as animações terem até sete minutos de duração favoreceria a incorporação das mesmas no planejamento de aulas, pois permitiriam eventuais intervenções pedagógicas visando a elaboração das informações por meio de outras estratégias didáticas.

Figura 5 - Amostra da categorização por análise de conteúdo dos vídeos de Fisiologia da plataforma $T E D-E d$.

\begin{tabular}{|c|c|c|c|c|c|c|}
\hline Título do vídeo & $\begin{array}{c}\text { Conceito } \\
\text { Inicial } \\
\text { (Tema-eixo) }\end{array}$ & $\begin{array}{l}\text { Conceito } \\
\text { Intermediário } \\
\text { (Contexto) }\end{array}$ & Conceito Final & $\begin{array}{c}\text { Área do } \\
\text { conhecimento } \\
\text { específico }(\mathrm{CNPq})\end{array}$ & $\begin{array}{c}\text { Área de } \\
\text { conhecimento } \\
\text { amplo } \\
(\mathrm{CNPq})\end{array}$ & Abordagem \\
\hline $\begin{array}{l}\text { The surprising cause } \\
\text { of stomach ulcers - } \\
\text { Rusha Modi }\end{array}$ & $\begin{array}{l}\text { Úlceras } \\
\text { estomacais }\end{array}$ & $\begin{array}{l}\text { Bactérias } \\
\text { provocam } \\
\text { úlceras } \\
\text { estomacais }\end{array}$ & $\begin{array}{l}\text { Fisiologia } \\
\text { do Sistema } \\
\text { Digestório }\end{array}$ & $\begin{array}{c}\text { Fisiologia de } \\
\text { Órgãos e Sistemas }\end{array}$ & Fisiologia & $\begin{array}{l}\text { Histórica/ } \\
\text { Científica }\end{array}$ \\
\hline $\begin{array}{l}\text { Why do we harvest } \\
\text { horseshoe crab } \\
\text { blood? - Elizabeth } \\
\text { Cox }\end{array}$ & $\begin{array}{l}\text { Defesas a } \\
\text { patógenos }\end{array}$ & $\begin{array}{c}\text { Aplicação } \\
\text { médica de } \\
\text { substâncias de } \\
\text { caranguejos }\end{array}$ & $\begin{array}{l}\text { Fisiologia do } \\
\text { Sistema de } \\
\text { defesa }\end{array}$ & $\begin{array}{l}\text { Fisiologia } \\
\text { Comparada }\end{array}$ & Fisiologia & Científica \\
\hline $\begin{array}{l}\text { The left brain vs. } \\
\text { right brain myth - } \\
\text { Elizabeth Waters }\end{array}$ & $\begin{array}{l}\text { Anatomo- } \\
\text { fisiologia } \\
\text { do cérebro } \\
\text { humano }\end{array}$ & $\begin{array}{l}\text { Constituição } \\
\text { Adaptativas do } \\
\text { cérebro }\end{array}$ & $\begin{array}{c}\text { Fisiologia do } \\
\text { Cérebro }\end{array}$ & $\begin{array}{c}\text { Fisiologia de } \\
\text { Órgãos e Sistemas }\end{array}$ & Fisiologia & $\begin{array}{l}\text { Histórica/ } \\
\text { Científica }\end{array}$ \\
\hline $\begin{array}{l}\text { How does caffeine } \\
\text { keep us awake? - } \\
\text { Hanan Qasim }\end{array}$ & Cafeína & $\begin{array}{c}\text { Ação da cafeína } \\
\text { no cérebro } \\
\text { humano } \\
\end{array}$ & $\begin{array}{c}\text { Fisiologia do } \\
\text { cérebro }\end{array}$ & $\begin{array}{c}\text { Fisiologia de } \\
\text { Órgãos e Sistemas }\end{array}$ & Fisiologia & Científica \\
\hline $\begin{array}{c}\text { What causes kidney } \\
\text { stones? - Arash } \\
\text { Shadman }\end{array}$ & Pedras nos rins & $\begin{array}{c}\text { Funcionamento } \\
\text { dos rins }\end{array}$ & $\begin{array}{c}\text { Fisiologia } \\
\text { do sistema } \\
\text { urinário }\end{array}$ & $\begin{array}{c}\text { Fisiologia de } \\
\text { Órgãos e Sistemas }\end{array}$ & Fisiologia & Científica \\
\hline $\begin{array}{c}\text { How do drugs affect } \\
\text { the brain? - Sara } \\
\text { Garofalo }\end{array}$ & Drogas & $\begin{array}{c}\text { Ação das } \\
\text { drogas no } \\
\text { cérebro }\end{array}$ & $\begin{array}{l}\text { Fisiologia do } \\
\text { Cérebro }\end{array}$ & $\begin{array}{c}\text { Fisiologia de } \\
\text { Órgãos e Sistemas }\end{array}$ & Fisiologia & Científica \\
\hline $\begin{array}{l}\text { How does your body } \\
\text { process medicine? - } \\
\text { Céline Valéry }\end{array}$ & Medicamentos & $\begin{array}{c}\text { Funcionamento } \\
\text { do } \\
\text { processamento } \\
\text { de } \\
\text { medicamentos } \\
\text { no corpo } \\
\text { humano } \\
\end{array}$ & $\begin{array}{l}\text { Fisiologia } \\
\text { do sistema } \\
\text { circulatório }\end{array}$ & $\begin{array}{c}\text { Fisiologia de } \\
\text { Órgãos e Sistemas }\end{array}$ & Fisiologia & Científica \\
\hline $\begin{array}{c}\text { How does asthma } \\
\text { work? - Christopher } \\
\text { E. Gaw }\end{array}$ & Asma & $\begin{array}{l}\text { Funcionamento } \\
\text { do sistema } \\
\text { respiratório }\end{array}$ & $\begin{array}{l}\text { Fisiologia } \\
\text { do sistema } \\
\text { respiratório }\end{array}$ & $\begin{array}{c}\text { Fisiologia de } \\
\text { Órgãos e Sistemas }\end{array}$ & Fisiologia & Científica \\
\hline $\begin{array}{l}\text { Oxygen's } \\
\text { surprisingly complex } \\
\text { journey through your } \\
\text { body - Enda Butler }\end{array}$ & $\begin{array}{l}\text { Transporte de } \\
\text { oxigênio }\end{array}$ & $\begin{array}{l}\text { Funcionamento } \\
\text { integrado } \\
\text { do sistema } \\
\text { respiratório e } \\
\text { circulatório }\end{array}$ & $\begin{array}{l}\text { Fisiologia } \\
\text { do sistema } \\
\text { respiratório }\end{array}$ & $\begin{array}{c}\text { Fisiologia de } \\
\text { Órgãos e Sistemas }\end{array}$ & Fisiologia & Científica \\
\hline $\begin{array}{l}\text { Why do we itch? - } \\
\text { Emma Bryce }\end{array}$ & Coceira & $\begin{array}{c}\text { Funcionamento } \\
\text { do sistema } \\
\text { nervoso }\end{array}$ & $\begin{array}{c}\text { Fisiologia } \\
\text { do sistema } \\
\text { nervoso }\end{array}$ & $\begin{array}{c}\text { Fisiologia de } \\
\text { Órgãos e Sistemas }\end{array}$ & Fisiologia & Científica \\
\hline
\end{tabular}

Fonte: As autoras. 


\section{CONSIDERaÇões FINAIS}

Este trabalho selecionou parâmetros de análise para alguns critérios técnicos, estéticos e pedagógicos, visando a seleção de vídeos curtos de animação para a utilização no ensino de Biologia.

Os vídeos animados de Biologia das plataformas TED-Ed: Lessons Worth of Sharing e o Kurzgesagt - In a Nutshell apresentam muitos dos princípios da animação definidos por Thomas e Johnson (1981), sendo que há diferenças marcantes quanto à aplicação do princípio "apelo" que foi considerado muito distinto nas duas plataformas. A plataforma Kurzgesagt - In a Nutshell disponibiliza um número menor de vídeos animados na área de Biologia, mas aplica melhor as cores e musicalidade em seus vídeos e isso acaba contribuindo para o aumento da presença do princípio do "apelo" nos seus vídeos.

Por sua vez, a plataforma TED-Ed: Lessons Worth of Sharing disponibiliza um grande número de vídeos animados que, a despeito do pouco uso do princípio "apelo", apresenta muitos outros princípios de animação considerados fundamentais para a boa qualificação das produções. A área do conhecimento mais representada nos vídeos de animação dessa plataforma é a fisiologia, seguida da zoologia. Curiosamente, verificou-se que há áreas de conhecimento biológico extremamente sub-representadas, como ecologia e genética, que contam com apenas, respectivamente, $5 \%$ e $6 \%$ dos vídeos publicados. Além disso, há áreas totalmente ausentes, como evolução. A análise dos vídeos demonstrou que a abordagem evolutiva está presente em alguns vídeos animados, por exemplo "A evolução do olho" ou "A evolução da genitália animal", mas os vídeos exibem os conceitos iniciais num contexto de funcionalidade sem estabelecer correlação direta com os processos evolutivos.

A despeito da dificuldade em se encontrar referências bibliográficas que discutam quais seriam os parâmetros de análise a serem considerados por professores na seleção para aplicação didática de vídeos curtos de animação, os resultados apresentados neste trabalho indicam que os vídeos animados das plataformas TED-Ed: Lessons Worth Sharing e Kurzgesagt - In a Nutshell mostram características técnicas, estéticas e pedagógicas possivelmente adequadas para o uso no ensino de biologia.

O presente trabalho indica um caminho para auxiliar os professores na escolha dos vídeos animados, visando permitir a efetiva incorporação dos mesmos como recurso didático para benefício dos momentos de ensino. Ressalta-se que, independentemente do professor aplicar os critérios de análise de vídeos curtos animados propostos aqui, ainda seria fundamental considerar a faixa etária dos alunos, a competência de leitura (das legendas), o perfil da turma e a organização espacial das salas de aulas. Além disso, seria interessante avaliar os impactos da utilização dos vídeos curtos para ampliar o entendimento da influência do uso pedagógico desses recursos no processo de ensino e aprendizagem de Biologia. 


\section{REFERÊNCIAS}

ALVES, B. M. Trilha Sonora : o cinema e seus sons. Novos Olhares v. 1, p. 90-95, 2012. Disponível em: <http://www.revistas.usp.br/novosolhares/article/view/55404>. Acesso em: abr. 2018.

BARDIN, L. Análise de Conteúdo. São Paulo: Editora Persona, 2016, 149 p.

BIElschowsKy, C. E.; PRATA, C. L. Portal Educacional do Professor do Brasil. Revista de Educacion, v. 352, p. 14, 2010.

BINOTTO, S. F. T.; BASSO, M. V. de A. Banco Internacional de Objetos Educacionais: um relato de experiência do Projeto Odin. Revista ACB, p. 174-193, 2012.

CNPQ. Tabela de Áreas do Conhecimento do CNPq. Data GramaZero - Revista de Informação v. 6, n. 5, p. 0-11, 2005. Disponível em: <http://www.dgz.org.br/dez11/Art_06. htm>. Acesso em: nov. 2017.

FREITAS, A. K. M. Psicodinâmica das cores em comunicação. Nucom, ISCA Faculdades, Limeira/SP, v. 4, n. 12, p. 3-20, 2007.

JUNIOR, W. A.; BARROS, D. M. V. Objetos de aprendizagem virtuais: material didático para a educação básica, 2005. Disponível em: <http://www.abed.org.br/congresso2005/por/pdf/006tcc1.pdf>. Acesso em: fev. 2018.

KURZGESAGT. Kurzgesagt - In a Nutshell: About. YouTube, junho de 2017. Disponível em: <https://www.youtube.com/user/Kurzgesagt/about>. Acesso em: mai. 2017.

MORAN, J. M. O Vídeo na Sala de Aula. Comunicação e Educação, v. 2, p. 27-35, 1995.

MORAN, J. M.; MASSETO, M. T.; BEHRENS, M. Ap. Novas tecnologias e mediação pedagógica. Campinas: Papirus, 2000.

ROSA, P. R. da S. Uma Introdução a Pesquisa Qualitativa Em Ensino de Ciências, p. 171, 2013.

SANTOS, R. de J. Uma Taxionomia para o uso de Vídeos Didáticos no Ensino de Matemática. Educação Matemática, Tecnologias Informáticas e Educação à Distância, Universidade Federal de Juiz de Fora, 2015. 
SCHNEIDER, C. K.; CAETANO, L.; RIBEIRO, L. O. M. Análise De Vídeos Educacionais no Youtube: Caracteres e Legibilidade. Novas Tecnologias na Educação v. 10, n. 1, p. 1-11, 2012.

SOUSA, R. P.; MOITA, F. M. C. da S. C.; CARVALHO, A. B. G. Tecnologias Digitais na Educação. Eduepb, 21 ed. Campina Grande/PB, 2011, 274 p.

SOUZA, R. W. de L. de. Modalidades e Recursos Didáticos para o Ensino de Biologia. Reb v. 7, n. 2, p. 124-142, 2014.

TED-ED. About TED-Ed. 2017. Disponível em: < https://ed.ted.com/about>. Acesso em: mai. 2017.

THOMAS, F.; JOHnSON, O. The illusion Of Life: Disney Animation. Disney Press, 1981. Capítulo 3.

TULGAN, B. Meet Generation $\mathbf{Z}$ : The second generation within the giant "Millennial" cohort. RainmakerThinking, Inc. p. 1-13, 2013. Disponível em: <http://rainmakerthinking.com/assets/uploads/2013/10/Gen-Z-Whitepaper.pdf>. Acesso em: mai. 2017.

DAdos das AUTORAS

Talitha Tiyomi Lima

Instituto Federal de Educação, Ciência e Tecnologia de São Paulo (IFS). São Paulo/SP Brasil. tatiyolima@gmail.com

Martha Cristina Motta Godinho Netto

Instituto Federal de Educação, Ciência e Tecnologia de São Paulo (IFS). São Paulo/SP Brasil.martha.godinho2@gmail.com

Submetido em: 11-12-2018

Aceito em: 6-9-2019 